\title{
The scopolamine-reversal paradigm in rats and monkeys: the importance of computer-assisted operant-conditioning memory tasks for screening drug candidates
}

\author{
Jerry J. Buccafusco $•$ Alvin V. Terry Jr • \\ Scott J. Webster • Daniel Martin • \\ Elizabeth J. Hohnadel • Kristy A. Bouchard • \\ Samantha E. Warner
}

Received: 18 May 2007 / Accepted: 30 June 2007 /Published online: 27 July 2007

(C) Springer-Verlag 2007

\begin{abstract}
Rationale The scopolamine-reversal model is enjoying a resurgence of interest in clinical studies as a reversible pharmacological model for Alzheimer's disease (AD). The cognitive impairment associated with scopolamine is similar to that in AD. The scopolamine model is not simply a cholinergic model, as it can be reversed by drugs that are noncholinergic cognition-enhancing agents.

Objectives The objective of the study was to determine relevance of computer-assisted operant-conditioning tasks in the scopolamine-reversal model in rats and monkeys.

Materials and methods Rats were evaluated for their acquisition of a spatial reference memory task in the Morris water maze. A separate cohort was proficient in performance of an automated delayed stimulus discrimination task (DSDT). Rhesus monkeys were proficient in the performance of an automated delayed matching-to-sample task (DMTS).

Results The AD drug donepezil was evaluated for its ability to reverse the decrements in accuracy induced by scopol-
\end{abstract}

J.J Buccafusco $(\bowtie) \cdot$ A. V. Terry Jr $\cdot$ S. J. Webster $\cdot$ D. Martin Alzheimer's Research Center, Department of Pharmacology and Toxicology, Medical College of Georgia,

Augusta, GA 30912, USA

e-mail: jbuccafu@mcg.edu

\section{J. J. Buccafusco}

Veterans Administration Medical Center,

Augusta, GA 30904-6285, USA

A. V. Terry Jr • E. J. Hohnadel $\cdot$ K. A. Bouchard · S. E. Warner Small Animal Behavior Core, Medical College of Georgia, Augusta, GA 30912, USA amine administration in all three tasks. In the DSDT and DMTS tasks, the effects of donepezil were delay (retention interval)-dependent, affecting primarily short delay trials. Donepezil produced significant but partial reversals of the scopolamine-induced impairment in task accuracies after $2 \mathrm{mg} / \mathrm{kg}$ in the water maze, after $1 \mathrm{mg} / \mathrm{kg}$ in the DSDT, and after $50 \mu \mathrm{g} / \mathrm{kg}$ in the DMTS task.

Conclusions The two operant-conditioning tasks (DSDT and DMTS) provided data most in keeping with those reported in clinical studies with these drugs. The model applied to nonhuman primates provides an excellent transitional model for new cognition-enhancing drugs before clinical trials.

Keywords Spatial memory · Delayed matching · Cognition · Scopolamine $\cdot$ Donepezil $\cdot$ Monkeys

\section{Introduction}

Amnestic agents such as the muscarinic receptor antagonists atropine and scopolamine have been used for decades in experimental animals to induce impairment in their performance of a variety of tasks requiring intact working and reference memory (for review, see Heise 1984; Bartus et al. 1987; Taffe et al. 1999). Scopolamine had been put to similar use in clinical studies more than 30 years ago (e.g., Drachman and Leavitt 1974). These early studies indicated that blockade of central muscarinic receptors could induce a pattern of cognitive impairment in young subjects reminiscent of that observed in the aged or in individuals with Alzheimer's disease (AD). Indeed, studies with anticholin- 
ergic drugs in animals and in humans helped trigger the concept that the cognitive impairment often associated with aging (Drachman and Leavitt 1974) or AD (Smith and Swash 1978) might be related to a central cholinergic deficit. In fact, the amnestic action produced in animals by antimuscarinic drugs, particularly scopolamine, has been widely used as a model for the characterization of potential cognition-enhancing drugs (see Ebert and Kirch 1998). For animal studies, however, pharmacological models of induced memory impairment have been suggested to be of limited value because they fail to replicate the pathological aspects and the progressive degenerative nature of AD (Van Dam and De Deyn 2006). A criticism often leveled at what might be termed the scopolamine-reversal test is the lack of versatility in the model, as scopolamine would be expected to produce a specific impairment in cholinergic (muscarinic) brain function. Although basal forebrain cholinergic neurons might be targeted primarily in early stages of $\mathrm{AD}$, there is no doubt that other neurotransmitter systems are also affected (see Rossor and Iversen 1986; Terry et al. 2003). AD affects cholinergic neurons in specific brain regions where the disease process leads to the decreased expression of specific subtypes of muscarinic cholinergic receptors. Presynaptic M2 receptors (located on cholinergic basal forebrain projection neurons) are depleted more severely than postsynaptic M1 receptors (Aubert et al. 1992). In contrast, scopolamine is relatively nonselective pharmacologically with respect to receptor subtypes, and the drug would not discriminate very much with respect to the brain region. It certainly would have little direct effect on noncholinergic neuronal pathways, although cholinergic neurons have functional interactions with a wide variety of neurotransmitter systems, which could be affected indirectly by the drug (Bartus et al. 1987).

Notwithstanding these limitations, the cognitive deficit produced by scopolamine in humans has been suggested to mimic very closely that associated with $\mathrm{AD}$ (Ebert and Kirch 1998). Another advantage is that scopolamine-induced cognitive impairment constitutes a reversible model that lends itself well to screening methods in drug discovery. The utility of the scopolamine model has been partially validated by the ability of centrally acting cholinomimetic drugs to reverse the effects of scopolamine on memory task performance. Early studies with the centrally acting cholinesterase inhibitor physostigmine demonstrated consistent but partial reversal of scopolamine-induced memory deficits (Bartus 1978; Mewaldt and Ghoneim 1978). More recent studies with the currently prescribed $\mathrm{AD}$ drugs rivastigmine, donepezil, and galantamine have reported similar scopolamine-reversal properties in the rat (Bejar et al. 1999; Takahata et al. 2005; van der Staay and Bouger 2005; de Bruin and Pouzet 2006; Lindner et al. 2006). However, cholinomimetic drugs are not the only pharmacological class to reverse scopolamine-induced memory deficits (Misane and Ogren 2003; Van Kampen et al. 2004; Lieben et al. 2005) attesting perhaps to the greater than expected versatility of the model.

The scopolamine-reversal model also has been applied to clinical studies in young (Molchan et al. 1990; Lines et al. 1993; Reidel et al. 1995) or healthy-aged subjects (Snyder et al. 2005). The importance of being able to evaluate new cognition-enhancing compounds in nonimpaired human populations is derived from the difficulty in obtaining participants with $\mathrm{AD}$ who are not already taking regimens of cholinesterase inhibitors. In preclinical studies, perhaps the two most widely used rodent tasks for studying or screening cognition-enhancing drugs are the inhibitory avoidance and the water maze tasks. However, clinical versions of these tasks are not well established. Computer-presented operantconditioning tasks designed for assessing the cognitive deficits associated with $\mathrm{AD}$ are available such as the CogState ${ }^{\mathrm{TM}}$ product (Collie and Maruff 2000; Collie et al. 2002) and the CANTAB ${ }^{\mathrm{TM}}$ product (Blackwell et al. 2004; Beglinger et al. 2005). Computer-presented cognitive test procedures are becoming more prevalent in the clinical cognitive-testing domain. Therefore, there would be some advantage to having available preclinical models that are more relevant than those often used for preclinical drug screening.

In this manuscript, we present two operant-conditioning tasks that we have used extensively for studying the effects of drugs modifying aspects of memory and cognition: the delayed stimulus discrimination task (DSDT) in rats (Terry et al. 1996, 1997, 1999a, b; Evans-Martin et al. 2000) and versions of the delayed matching-to-sample task (DMTS) in monkeys (see, Paule et al. 1998; Prendergast et al. 1998; Buccafusco and Terry 2000; Buccafusco et al. 2002; Bain et al. 2003). The scopolamine-reversal model has not been studied in either of these tasks, particularly with regard to their serving as preclinical models for AD drug discovery.

\section{Materials and methods}

\section{Rat subjects}

Male albino Wistar rats and Long-Evans rats, 2-3 months old, were used in the Morris water maze task and the DSDT, respectively. The two strains were selected based on previous experience in the tasks. For example, more than $80 \%$ of Long-Evans rats reached criteria in the DSDT, whereas only about $50 \%$ of Wistar rats routinely learn the task. Both strains were obtained from Harlan, Indianapolis, $\mathrm{IN}$, and initially housed in pairs in polycarbonate cages with Bed-O-Cob ${ }^{\circledR}$ bedding in a temperature-controlled room $\left(25^{\circ} \mathrm{C}\right)$ with a 12-h light/dark cycle with free access to food (Teklad Rodent Diet 8604 pellets, Harlan, Madison, 
WI). All rats were handled beginning the day after arrival and therefore received 2 weeks of handling before the initiation of behavioral testing. One week before testing in the DSDT and throughout the rest of the study, food intake was restricted to approximately $85 \%$ of ad libitum consumption. Additional food was given on weekends and holidays (if necessary) to maintain the weight of each rat at approximately $85 \%$ of its freely fed weight.

All behavioral experiments were conducted in rooms equipped with white noise generators (San Diego Instruments, San Diego, CA) set to provide a constant background level of $70 \mathrm{~dB}$ and ambient lighting of approximately 25 30 lux (lumen $/ \mathrm{m}^{2}$ ). Animals were transferred (in their home cages) to the behavioral testing rooms each morning approximately $30 \mathrm{~min}$ before the beginning of experiments. All procedures used during this study were reviewed and approved by the Medical College of Georgia Institutional Animal Care and Use Committee and are consistent with the guidelines of the Association for Assessment and Accreditation of Laboratory Animal Care. Measures were taken to minimize pain or discomfort in accordance with the National Institutes of Health Guide for the Care and Use of Laboratory Animals (NIH Publications no. 80-23), revised 1996. Significant efforts were also made to minimize the total number of animals used while maintaining statistically valid group numbers.

\section{The Morris water maze task}

Water maze experiments were performed as previously described (Terry et al. 1999a, b). The swimming activity of each rat was monitored via a television camera mounted overhead. Parameters that were analyzed included the latency to find the platform, total distance traveled, and time and distance spent in each quadrant (Actimetrics, Evanston, IL). The daily order of entry into individual quadrants was nonsystematically assigned such that all four quadrants were used once every 2 training days. Twentyfour hours after the hidden platform trial, probe trials were conducted in which the platform was removed from the pool to measure spatial bias for the previous platform location. After probe trials, a visible platform test was performed as a general estimate of visual acuity. A total of 61 rats participated in the four cohorts of the water maze study: 19 for the saline (vehicle)-treated saline controls; 16 rats were treated with $0.1 \mathrm{mg} / \mathrm{kg}$ of scopolamine followed $15 \mathrm{~min}$ later by saline; ten rats were treated with $0.1 \mathrm{mg} / \mathrm{kg}$ of scopolamine $\mathrm{HBr}$ followed $15 \mathrm{~min}$ later by $1 \mathrm{mg} / \mathrm{kg}$ of donepezil $\mathrm{HCl}$; and 16 rats were treated with $0.1 \mathrm{mg} / \mathrm{kg}$ of scopolamine followed $15 \mathrm{~min}$ later by $2 \mathrm{mg} / \mathrm{kg}$ of donepezil. Both injections were made by the subcutaneous route $(1 \mathrm{ml} / \mathrm{kg})$, the first injection made at the nape of the neck and the second over the thigh. All drug doses refer to the respective salts.
The delayed stimulus discrimination task

Rats were trained and tested in sound-attenuated operantconditioning chambers $(27.9 \times 29.2 \times 30.5 \mathrm{~cm})$ that were computer automated with levers centered on each side of a feed box and separated $140 \mathrm{~mm}$ (center to center). Details of the procedure have been previously reported (Terry et al. 1999a, b). The animals were trained to discriminate between the light and the tone. For one half of the subjects, the reward was provided only on the right side after a trial that began with the presentation of a light (for half of the animals), whereas after trials beginning with the presentation of a tone, only a response to the left side was rewarded (i.e., for half of the animals). The reverse association was used for the other half of the animals. Pneumatically operated internal doors were used to diminish the ability of animals to position themselves on a particular side near one of the levers, after the stimulus. Immediately after the stimulus, two delay intervals, each associated an equal number of times with the light and the tone, were presented repetitively to comprise a daily test session of 60 trials. For this study, 12 rats were trained to the criteria in the DSDT. Each rat received every regimen in the protocol over the course of the study. For each regimen, the two injections were spaced $15 \mathrm{~min}$ apart with saline or donepezil always after the scopolamine administration. Each regimen was replicated during sessions in which the set of short-delay trials preceded long-delay trials and during sessions in which the set of long-delay trials preceded the short-delay trials. Thus, each animal received every drug regimen in the study four times, except for the saline-saline condition, which was replicated five times over the course of the study to insure a return to baseline conditions after each regimen. The sequence of six regimens was randomized throughout the study. Long-delay intervals for the subjects ranged from 20 to $60 \mathrm{~s}$, averaging $34.2 \pm 5.2 \mathrm{~s}$.

\section{Primate subjects}

Male and female Rhesus monkeys (Macaca mulatta) were individually housed at the Animal Behavior Center of the Medical College of Georgia in stainless steel cages composed of multiple $127 \times 71 \times 66$-cm units. To promote psychological well-being, toys and foraging tubes were provided routinely, and monkeys were allowed to observe television programs each afternoon after testing and on weekends. The subjects were well trained ( $>100$ individual sessions) in the DMTS task. The animals were maintained on tap water (unlimited) and standard laboratory monkey chow (Harlan Teklad Laboratory monkey diet, Madison, WI) supplemented with fruits and vegetables. The animals were maintained on a feeding schedule in which all food was removed from cages at about 06:30 hours and replaced 
after completion of testing of all subjects for the day (at about 16:30 hours). During testing, additional food intake was derived from 300-mg food pellets (commercial composition of standard monkey chow and banana flakes, Noyes Precision food pellets, P.J. Noyes, Lancaster, NH) obtained during experimental sessions. On weekends, animals were fed without time restrictions. The monkeys were maintained on a 12-h light-dark cycle and were tested each weekday between 09:00 and 14:00 hours. Room temperature and humidity was maintained at $22 \pm 0.6^{\circ} \mathrm{C}$ and $52 \pm 2 \%$, respectively. In addition to the demographic information provided in Table 1 , each of the subjects had participated in one or more previous studies in which potential cognitive-enhancing agents were evaluated. The drugs in question were proprietary agents, and so no description of their pharmacological properties can be disclosed, other than they were short-acting compounds and they were administered during acute studies no more than twice per week. No side effects or long-lasting effects were associated with any of these earlier studies, and all animals were provided at least a 4-week washout period before the present series. Finally, for the female animals in the study, testing was administered between menstrual cycles.

The standard delayed matching-to-sample task

Test panels attached to each animal's home cage presented the DMTS by using a computer-automated system (Buccafusco et al. 2002). A 38-cm diagonal touch-sensitive screen (AccuTouch LCD Panelmount TouchMonitor)/pellet dispenser unit (Med Associates) mounted in a light-weight aluminum chassis was attached to the home cage. The stimuli included red, blue, and yellow rectangles. A correct (matching) choice was reinforced. Nonmatching choices

Table 1 Subject information-rhesus monkeys

\begin{tabular}{|c|c|c|c|c|c|c|}
\hline \multirow{2}{*}{$\frac{\text { ID number }}{18}$} & \multirow{2}{*}{$\frac{\text { Sex }}{M}$} & \multirow{2}{*}{$\begin{array}{l}\text { Age (years) } \\
10\end{array}$} & \multirow{2}{*}{$\begin{array}{l}\text { Weight }(\mathrm{kg}) \\
9.4\end{array}$} & \multicolumn{3}{|c|}{ Delay Intervals (s) } \\
\hline & & & & 30 & 90 & 150 \\
\hline 23 & $\mathrm{M}$ & 18 & 9.4 & 5 & 25 & 50 \\
\hline 24 & M & 11 & 7.6 & 20 & 60 & 100 \\
\hline 125 & M & 7 & 10 & 10 & 20 & 40 \\
\hline 147 & M & 8 & 10.8 & 15 & 30 & 70 \\
\hline 213 & $\mathrm{~F}$ & 25 & 9.1 & 15 & 25 & 80 \\
\hline 308 & M & 9 & 10 & 15 & 45 & 90 \\
\hline 424 & M & 23 & 13.8 & 35 & 75 & 150 \\
\hline 437 & M & 24 & 7 & 20 & 40 & 60 \\
\hline 446 & $\mathrm{~F}$ & 27 & 7.2 & 10 & 15 & 40 \\
\hline 517 & $\mathrm{~F}$ & 22 & 6.2 & 5 & 10 & 20 \\
\hline 573 & M & 10 & 10.2 & 5 & 10 & 20 \\
\hline 618 & M & 10 & 11.2 & 5 & 10 & 15 \\
\hline 641 & $\mathrm{~F}$ & 26 & 3.8 & 25 & 35 & 55 \\
\hline 667 & $\mathrm{~F}$ & 29 & 8 & 3 & 5 & 7 \\
\hline 671 & $\mathrm{~F}$ & 29 & 4.2 & 3 & 5 & 7 \\
\hline 674 & $\mathrm{~F}$ & 26 & 6.9 & 3 & 5 & 10 \\
\hline 683 & $\mathrm{~F}$ & 26 & 6.3 & 10 & 60 & 120 \\
\hline 696 & $\mathrm{M}$ & 29 & 7.2 & 2 & 3 & 4 \\
\hline 759 & M & 20 & 10.4 & 25 & 50 & 120 \\
\hline 977 & M & 26 & 11.6 & 6 & 9 & 12 \\
\hline 979 & $\mathrm{~F}$ & 24 & 10.6 & 6 & 10 & 15 \\
\hline 987 & M & 12 & 9.5 & 5 & 7 & 10 \\
\hline 993 & M & 12 & 10.3 & 7 & 15 & 20 \\
\hline $8 \mathrm{LY}$ & $\mathrm{F}$ & 23 & 12.4 & 5 & 7 & 10 \\
\hline $92 \mathrm{~F}$ & $\mathrm{~F}$ & 13 & 7.5 & 3 & 5 & 7 \\
\hline B18 & $\mathrm{F}$ & 21 & 4.9 & 10 & 30 & 80 \\
\hline C8R & $\mathrm{M}$ & 5 & 5.6 & 3 & 5 & 7 \\
\hline E1V & $\mathrm{F}$ & 11 & 6 & 10 & 15 & 20 \\
\hline EX0 & $\mathrm{F}$ & 11 & 8.2 & 10 & 15 & 20 \\
\hline H1V & $\mathrm{F}$ & 19 & 6.2 & 3 & 5 & 7 \\
\hline S11 & M & 31 & 11.8 & 6 & 12 & 18 \\
\hline 9SX & $\mathrm{F}$ & 11 & 6.6 & 5 & 7 & 10 \\
\hline Mean & & 18.42 & 8.48 & 10.30 & 23.03 & 43.76 \\
\hline SEM & & 1.38 & 0.43 & 1.49 & 3.90 & 7.68 \\
\hline
\end{tabular}


were neither reinforced nor punished. The intertrial interval was $5 \mathrm{~s}$ (administered after both correct and incorret choices), and each session consisted of 96 trials. The presentation of stimulus color, choice colors, and choice position (left or right on the screen) were fully counterbalanced so as to relegate nonmatching (mediating) strategies to chance levels of accuracy. Five different presentation sequences were rotated through each daily session to prevent the subjects from memorizing the first several trials. The duration for each delay interval was adjusted until three levels of performance difficulty were obtained: zero delay $(85-100 \%$ of trials answered correctly), short-delay interval (75-84\% correct), medium-delay interval $(65-74 \%$ correct $)$, and long-delay interval (55-64\% correct) representing each animal's limit in terms of DMTS performance. The assignment of retention intervals based upon an individual's baseline levels of task accuracy is necessary to avoid ceiling effects in the most proficient animals during drug studies while also serving to insure that each animal begins testing at relatively the same level of task difficulty (Paule et al. 1998). A 3-min interval was allowed for the animal to respond after a sample or choice presentation. Failure to respond initiated the next trial in the sequence. Each trial that did not receive a response was deemed not applicable and the percent of correct trials was determined only from the total number of trials actually completed. In addition to session accuracy and the number of completed trials, two (median) response latencies also were measured: the "sample latency," which is the time between presentation of the sample color and the animal touching the sample rectangle, and the "choice latency," which is the time between presentation of the choice rectangles and the animal touching one of the choice rectangles. Latencies were recorded as the nearest 100th of a second.

For the series with donepezil (intramuscular [i.m.]) alone, study animals included 16 male and 16 female Rhesus monkeys representing a wide age range; the average age of the group was 18.8 years. Additional subject information is provided in Table 1. All 32 subjects did not participate in every study described below, but many were used in experiments in which certain drug or vehicle administrations were replicated up to ten times in some cases. The data below were compiled from a number of individual smaller studies conducted over the past 2 years. For the series with orally administered donepezil, subjects 24, 424, 446, 517, 683, E1V, and 9SX (males and females) were used. For the series with scopolamine alone, subjects: 618 , $18,24,125,308$, and 573 (all males) participated in the study. Each animal was tested during the ten sessions (replicates) of the standard DMTS task (no drug or vehicle pretreatment), during one session after the $5-\mu \mathrm{g} / \mathrm{kg}$ dose, during two sessions after the $15-\mu \mathrm{g} / \mathrm{kg}$ dose, and after eight sessions of the $20-\mu \mathrm{g} / \mathrm{kg}$ dose. For the series that included scopolamine reversal, nine subjects participated in this study: 18, 24, 125, 147, 308, 573, 618, 987, and 993 (all males). Each animal was tested during the ten sessions (replicates) of the standard DMTS task, after eight sessions of the $20-\mu \mathrm{g} / \mathrm{kg}$ dose of scopolamine (vehicle pretreatment), after one session in which $5 \mu \mathrm{g} / \mathrm{kg}$ of donepezil was administered before $20 \mu \mathrm{g} / \mathrm{kg}$ of scopolamine, after four sessions in which $10 \mu \mathrm{g} / \mathrm{kg}$ of donepezil was administered before $20 \mu \mathrm{g} / \mathrm{kg}$ of scopolamine, after four sessions in which $25 \mu \mathrm{g} / \mathrm{kg}$ of donepezil was administered before $20 \mu \mathrm{g} / \mathrm{kg}$ of scopolamine, after two sessions in which $50 \mu \mathrm{g} / \mathrm{kg}$ of donepezil was administered before $20 \mu \mathrm{g} / \mathrm{kg}$ of scopolamine, after one session in which $100 \mu \mathrm{g} / \mathrm{kg}$ of donepezil was administered before $10 \mu \mathrm{g} / \mathrm{kg}$ of scopolamine, and after one session in which $125 \mu \mathrm{g} / \mathrm{kg}$ of donepezil was administered before $20 \mu \mathrm{g} / \mathrm{kg}$ of scopolamine.

\section{Drug solutions}

All drugs were dissolved in sterile normal saline. New solutions were prepared just before each day's experiments. Doses refer to the respective salts scopolamine hydrobromide (Sigma-Aldridge, St. Louis, MO) and donepezil hydrochloride (a gift from Pfizer).

\section{Statistical analyses}

Data were analyzed by use of a multifactorial analysis of variance (ANOVA) with repeated measures (SAS, JMP statistical software package). The effects of treatment, dose, time of testing (on the day of drug administration vs sessions run $24 \mathrm{~h}$ after drug administration), etc., and all crosswise interactions were assessed. An orthogonal multicomparison $t$ test was used to compare individual means. Error values denoted by \pm indicated the standard error of the mean. The difference between means from experimental groups was considered significant at the $P<0.05$ level (twosided test). Because when both donepezil and scopolamine were tested in the same study, the null hypothesis pertained to the ability of donepezil to reverse the effects of scopolamine; the primary comparisons were between the scopolamine control group and the other treatment groups.

\section{Results}

Scopolamine reversal-Morris water maze

The swim latencies for water maze acquisition are presented in Fig. 1a. There was a statistically significant effect of drug treatment $\left(F_{3,298}=15.3, P<0.0001\right.$; no interactions $)$. On the first day of testing, however, there were no differences among the groups in mean swim latencies. Beginning on test day 3, the scopolamine control group exhibited an impairment in 
a

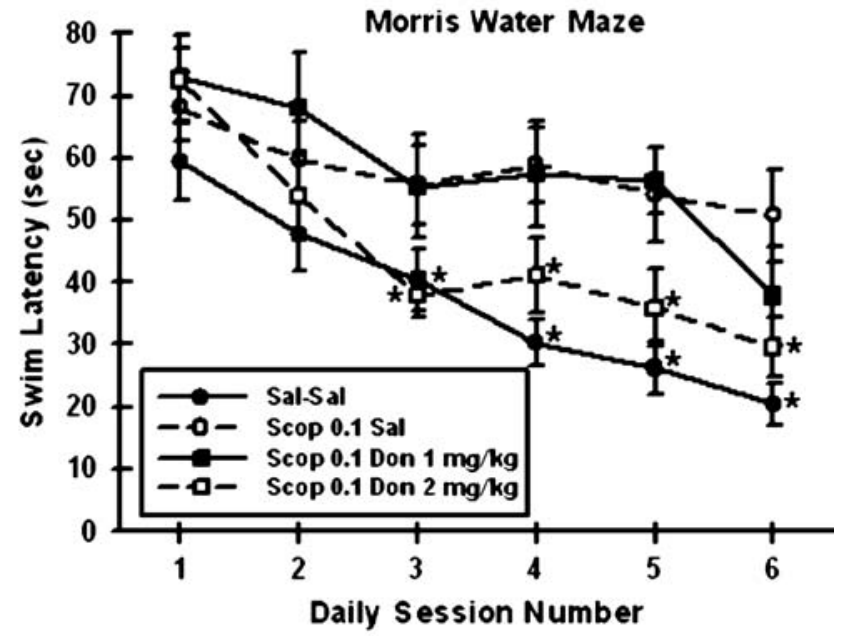

b

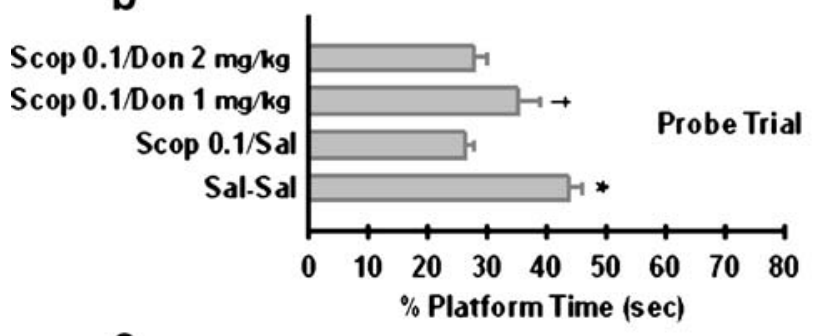

C

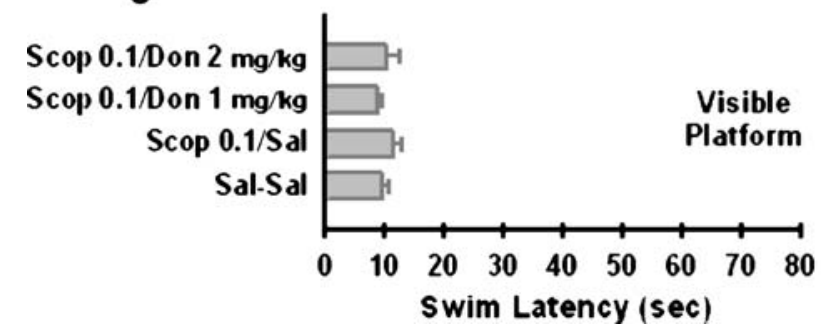

Fig. 1 Comparison of the effects of drug vehicle followed by drug vehicle $(S a l-S a l)$, scopolamine $(0.1 \mathrm{mg} / \mathrm{kg})$ followed by vehicle $(S c o p$ $0.1 / \mathrm{Sal})$, scopolamine $(0.1 \mathrm{mg} / \mathrm{kg})$ followed by donepezil $1 \mathrm{mg} / \mathrm{kg}$ (Scop 0.1/Don $1 \mathrm{mg} / \mathrm{kg}$ ), and scopolamine $(0.1 \mathrm{mg} / \mathrm{kg}$ ) followed by donepezil $2 \mathrm{mg} / \mathrm{kg}$ (Scop 0.1/Don $1 \mathrm{mg} / \mathrm{kg}$ ) on the ability of rats a to acquire proficiency in the Morris water maze task, b in their performance of the subsequent probe trial, and $\mathbf{c}$ in their performance of the visible platform trial. Asterisk, significantly different from respective mean values in the Scop 0.1/Sal group, $P<0.05$

task performance relative to the saline-saline control group, which was maintained through test day $6(t=5.9, P<0.0001)$. Administration of $1 \mathrm{mg} / \mathrm{kg}$ of donepezil failed to reverse the scopolamine-induced increase in swim latency. When scopolamine was followed by the $2-\mathrm{mg} / \mathrm{kg}$ dose of donepezil, task latencies were significantly decreased relative to the scopolamine-saline group ( $t=3.6, P=0.0004)$. Scopolamine produced a slight but significant $\left(F_{3,298}=25.6, P<0.0001\right.$; no interactions) increase in average swim speed $(26.6 \mathrm{~cm} / \mathrm{s})$ relative to the saline-saline control group $(23.1 \mathrm{~cm} / \mathrm{s})$. Obviously, this increase in average swim speed (data not shown) in the scopolamine group could not explain the increase in swim latencies. Neither of the scopolaminedonepezil groups exhibited different average swim speeds from the saline-saline group.

Data for the probe session are presented in Fig. 1b. These data were not as straightforward as were the swim latencies during the standard sessions. Although average time spent over the platform area was decreased in the scopolamine-saline group relative to the control salinesaline group $\left(F_{3,13}=8.2, P=0.003\right.$, no interactions; $t=4.6, P$ $=0.0005$ ), neither dose of donepezil reversed the scopolamine-induced impairment in this session. The $1-\mathrm{mg} / \mathrm{kg}$ dose of donepezil partly reversed the scopolamine-induced impairment, but the effect was only nearly statistically significant $(t=1.8, P=0.091)$. In the visible platform test, on average, each of the cohorts swam to the platform within $12 \mathrm{~s}$ (Fig. 1c). There were no differences among the groups.

Scopolamine reversal—DSDT

The data for the effect of the drug regimens on accuracy in the DSDT are presented in Fig. 2. Under control conditions and for each regimen in the study, there was a significant delay-dependent decline in task accuracy from short- to long-delay trials $\left(F_{1,937}=245.0, P<0.0001\right.$; independent factor). There also was a significant effect of drug treatment as an independent factor $\left(F_{5,937}=59.3, P<0.0001\right)$ and as an

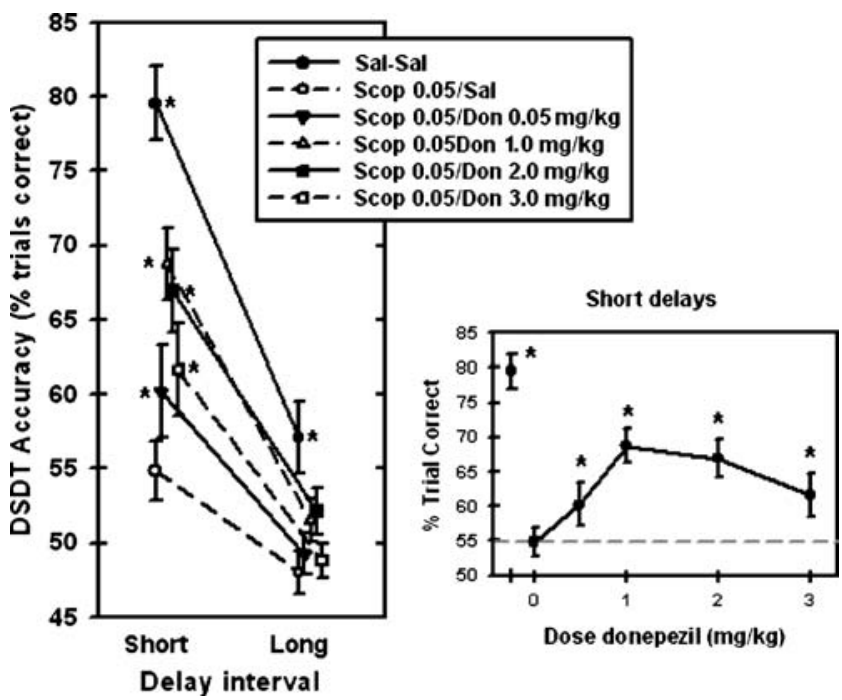

Fig. 2 Comparison of the effects of drug vehicle followed by drug vehicle $(\mathrm{Sal}-\mathrm{Sal})$, scopolamine $(0.05 \mathrm{mg} / \mathrm{kg})$ followed by vehicle (Scop $0.05 / \mathrm{Sal})$, scopolamine $(0.05 \mathrm{mg} / \mathrm{kg})$ followed by donepezil $1 \mathrm{mg} / \mathrm{kg}$ (Scop/Don $1.0 \mathrm{mg} / \mathrm{kg})$, scopolamine $(0.05 \mathrm{mg} / \mathrm{kg})$ followed by donepezil $2 \mathrm{mg} / \mathrm{kg}$ (Scop/Don $2.0 \mathrm{mg} / \mathrm{kg}$ ), and scopolamine $(0.05 \mathrm{mg} / \mathrm{kg}$ ) followed by donepezil $3 \mathrm{mg} / \mathrm{kg}$ (Scop/Don $3 \mathrm{mg} / \mathrm{kg}$ ) on DSDT accuracies by rats well trained in the task. Asterisk, significantly different from respective mean values in the Scop 0.05 / Sal group, $P<0.05$. Inset: The effect of donepezil in scopolaminepretreated rats on short-delay trial accuracy plotted as a function of donepezil dose. The first data point in the upper left is the mean value for short-delay accuracy for the Scop $0.05 /$ Sal group 
interaction with delay interval $\left(F_{5,937}=10.9, P<0.0001\right)$. Scopolamine $(0.05 \mathrm{mg} / \mathrm{kg})$ produced a dramatic and significant decrease in both short-delay trial accuracy $(t=13.4$, $P<0.0001)$ and long-delay trial accuracy $(t=4.9, P<0.0001)$ relative to the saline-saline group. The decrement in shortdelay task accuracy produced by scopolamine was significantly inhibited when each of the four doses of donepezil was added to the regimen $(t=2.2,5.8,5.1$, and 2.9 , respectively, for the $0.05,1-, 2-$, and $3-\mathrm{mg} / \mathrm{kg}$ doses; $P<0.03$ ). These data are plotted as a function of the dose of donepezil in the inset to Fig. 2. Although donepezil significantly reversed the amnestic action of scopolamine, the effect was not complete amounting to only about $50 \%$ of the task accuracy in the saline-saline group. The decrement in long-delay task accuracy produced by scopolamine was not significantly inhibited when donepezil was added to the regimen, although there was a nearly significant effect in the group that received the $2-\mathrm{mg} / \mathrm{kg}$ dose of donepezil $(t=1.7, P=0.085)$.

The data for the effect of the drug regimens on latencies in the DSDT are presented in Fig. 3. Under control conditions and for each regimen in the study, there was a significant delay-dependent decline in task latencies from short- to long-delay trials $\left(F_{1,937}=181.3, P<0.0001\right)$. Thus, the more difficult trials were associated with a more rapid response to choice presentation. There also was a significant effect of drug treatment as an independent factor $\left(F_{5,937}=15.2, P<0.0001\right)$ and as an interaction with delay

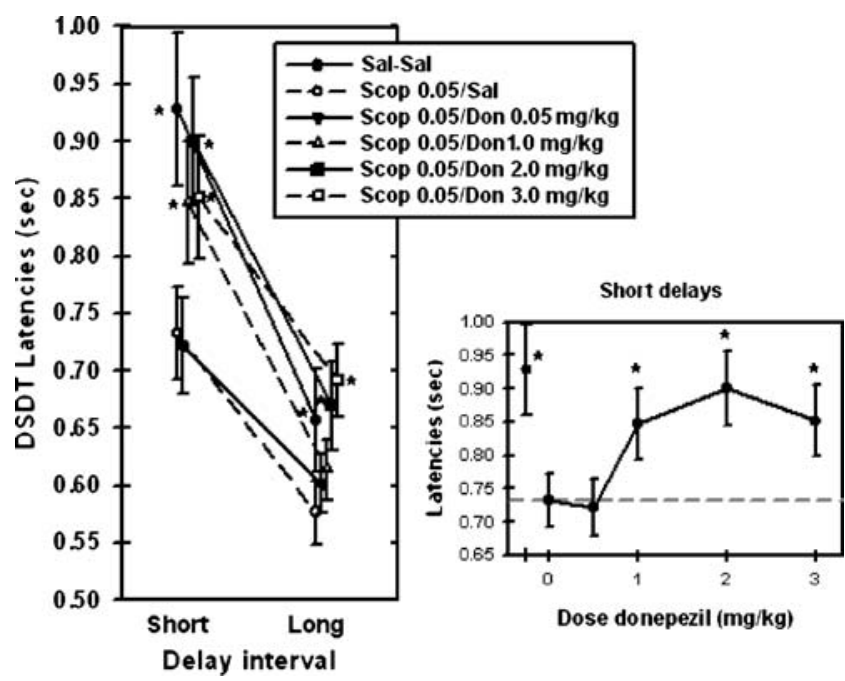

Fig. 3 Comparison of the effects of drug vehicle followed by drug vehicle $(\mathrm{Sal}-\mathrm{Sal})$, scopolamine $(0.05 \mathrm{mg} / \mathrm{kg})$ followed by vehicle (Scop $0.05 / \mathrm{Sal})$, scopolamine $(0.05 \mathrm{mg} / \mathrm{kg})$ followed by donepezil $1 \mathrm{mg} / \mathrm{kg}$ (Scop/Don $1.0 \mathrm{mg} / \mathrm{kg})$, scopolamine $(0.05 \mathrm{mg} / \mathrm{kg})$ followed by donepezil $2 \mathrm{mg} / \mathrm{kg}$ (Scop/Don $2.0 \mathrm{mg} / \mathrm{kg}$ ), and scopolamine $(0.05 \mathrm{mg} / \mathrm{kg}$ ) followed by donepezil $3 \mathrm{mg} / \mathrm{kg}$ (Scop/Don $3 \mathrm{mg} / \mathrm{kg}$ ) on DSDT median latencies by rats well trained in the task. Asterisk, significantly different from respective mean values in the Scop 0.05/ Sal group, $P<0.05$. Inset: The effect of donepezil in scopolaminepretreated rats on short-delay trial latency plotted as a function of donepezil dose. The first data point in the upper left is the mean value for short-delay accuracy for the Scop $0.05 /$ Sal group interval $\left(F_{5,937}=4.2, P=0.0008\right)$. Scopolamine $(0.05 \mathrm{mg} / \mathrm{kg})$ produced a dramatic and significant decrease in both shortdelay trial latency $(t=6.6, P<0.0001)$ and long-delay trial latency $(t=2.7, P=0.007)$ relative to the saline-saline group. The decrement in short-delay task latency produced by scopolamine was significantly inhibited when each of the 1-, 2-, and 3-mg/kg doses of donepezil was added to the regimen ( $t=3.0,4.4$, and 3.1, respectively; $P<0.003)$. These data are plotted as a function of dose of donepezil in the inset to Fig. 3. The $2-\mathrm{mg} / \mathrm{kg}$ dose nearly completely reversed the decrease in short-delay task latency produced by scopolamine. The decrement in long-delay task latency produced by scopolamine also was significantly inhibited when either the 2- or the $3-\mathrm{mg} / \mathrm{kg}$ dose of donepezil was added to the regimen ( $t=2.4$ and 3.0, respectively; $P<0.02$ ).

The effect of donepezil on DMTS task accuracies

Because of the paucity of preclinical studies of donepezil in monkeys relative to those in rodents, we elected first to examine the effect of the cholinesterase inhibitor alone on DMTS task performance in macaques. As a group, the performance accuracies in the standard DMTS task approximated the criteria set forth above: zero delay, $86.9 \%$, short delay, $75.5 \%$, medium delay, $63.5 \%$, and long delay, $58.7 \%$ trials correct. In general, vehicle sessions were run at the beginning, during, and at the completion of a drug dose study. Donepezil was administered no more than twice per week in a random series of doses: $10,25,50$, and $100 \mu \mathrm{g} / \mathrm{kg}$, i.m. Task accuracies as a function of delay interval are presented in Fig. 4. Statistical analysis indicated a significant effect of drug treatment $\left(F_{4,683}=2.58, P=0.036\right.$; independent factor). Examination of the memory retention curves shown in Fig. 1 suggested that task improvement was relegated primarily to long-delay trials. Statistically, mean accuracies after the 25- $(t=2.2, P=0.026), 50-(t=2.4$, $P=0.015)$, and $100-\mu \mathrm{g} / \mathrm{kg}(t=2.8, P=0.006)$ doses were significantly different from the respective long-delayvehicle means. During sessions run $24 \mathrm{~h}$ after drug administration, task accuracies on average were still greater than vehicle means (Fig. 1, inset), although the effect was not statistically significant. Although the subjects ages ranged from 5 to 31 years, there was no significant correlation between average (all four delays) DMTS accuracy after donepezil administration and subject age $\left(r^{2}=0.0412\right.$, $P=0.32$ ). There also was no significant correlation between age and long-delay accuracy after donepezil.

Because donepezil is administered orally for the treatment of $\mathrm{AD}$, we administered the drug by this route to seven subjects. Donepezil was administered 30 min before testing to account for the slow rate of drug distribution from the oral route. A dose range that was overlapping but higher than the i.m. dose range was used $(50-400 \mu \mathrm{g} / \mathrm{kg})$. The data 


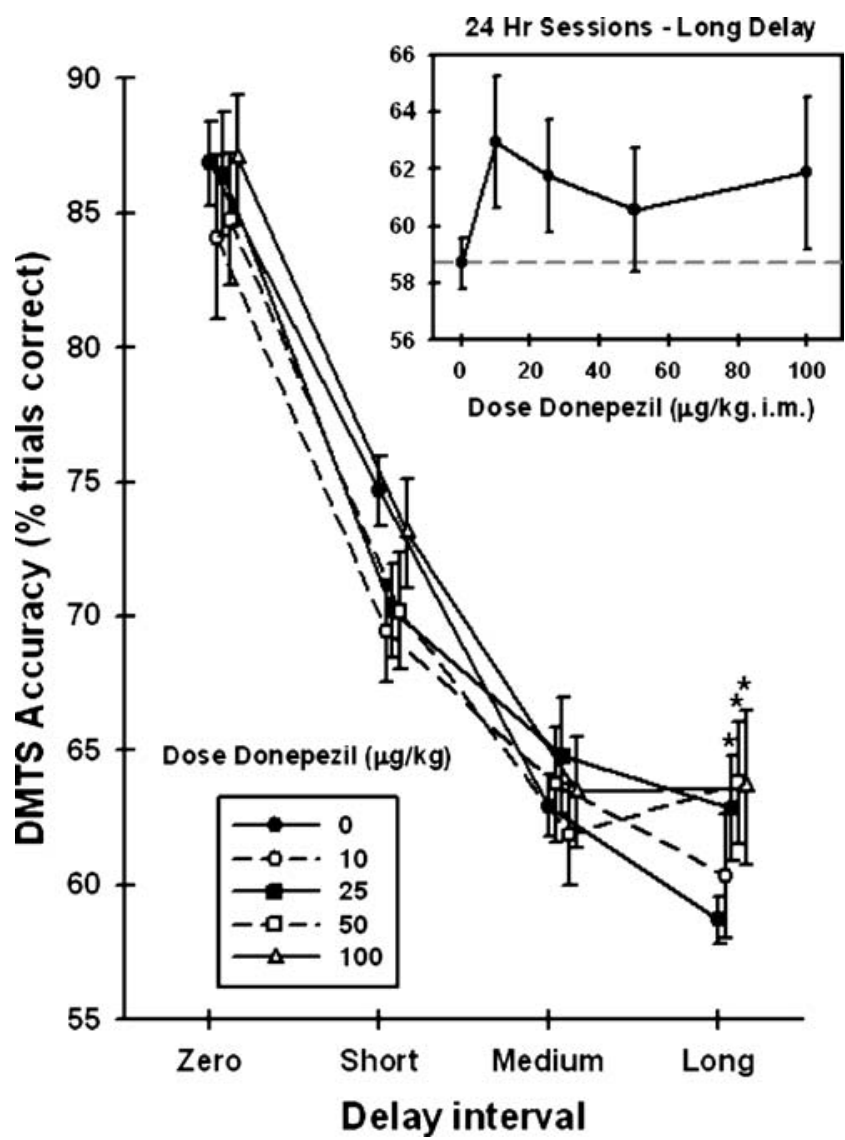

Fig. 4 The effect of i.m. administration of four doses of donepezil on the performance accuracy by Rhesus monkeys well trained in the DMTS task. Zero, Short, Medium, and Long refer to delay (retention) intervals. Asterisk, significantly different from respective mean values in the vehicle $(0 \mu \mathrm{g} / \mathrm{kg})$ group, $P<0.05$. Inset: The effect of donepezil on long-delay trial accuracy during sessions run $24 \mathrm{~h}$ after drug administration plotted as a function of donepezil dose

are presented in Fig. 5. Although the profile of the response to donepezil after oral administration was similar to that after i.m. injection (predominant improvement during longdelay trials), the effect of the drug given by oral route was not statistically significant from the vehicle. When considered alone and in comparison with the task accuracies obtained from the i.m. administration during long-delay trials, the maximal responses relative to the vehicle were not that different (Fig. 6). After i.m. administration of donepezil, long-delay trial accuracies were improved over the three highest doses relative to the vehicle. After oral administration, the maximal effect of donepezil peaked after the lowest $(50 \mu \mathrm{g} / \mathrm{kg})$ dose and quickly returned toward vehicle levels as the dose was increased.

The effect of scopolamine on DMTS task accuracies

Scopolamine treatment (Fig. 7) produced a dose-dependent $\times$ delay-dependent decrease in task accuracies associated pri- marily with short- and medium-delay trials $\left(F_{9,496}=5.16\right.$, $P<0.0001)$. Paradoxically, the lowest dose $(5 \mu \mathrm{g} / \mathrm{kg})$ actually increased long-delay accuracy. Statistically, scopolamine decreased accuracies associated with zero-delay trials after the $20-\mu \mathrm{g} / \mathrm{kg}$ dose $(t=2.7, P=0.008)$, with short-delay trials after the 15 - and $20-\mu \mathrm{g} / \mathrm{kg}$ doses $(t=2.0, P=0.048 ; t=10.9$, $P<0.0001)$, with medium delays after the $15-$ and $20-\mu \mathrm{g} / \mathrm{kg}$ doses $(t=1.9, P=0.063 ; t=9.2, P<0.0001)$, and with long delays after the $20-\mu \mathrm{g} / \mathrm{kg}$ dose $(t=5.4, P<0.0001)$. After the $5-\mu \mathrm{g} / \mathrm{kg}$ dose, long-delay accuracy was statistically increased relative to its respective vehicle mean $(t=2.6, P=0.010)$. Scopolamine treatment increased median choice latencies $\left(F_{3,118}=4.92, P<0.003\right)$, although the effect was relegated to the $20-\mu \mathrm{g} / \mathrm{kg}$ dose $(t=3.4, P=0.001)$. The median latency during vehicle sessions was $2.71 \pm 0.13 \mathrm{~s}$; after the $20-\mu \mathrm{g} / \mathrm{kg}$ dose, the median latency was $3.24 \pm 0.19 \mathrm{~s}$.

\section{Scopolamine reversal-DMTS}

In this series, donepezil was administered i.m. $10 \mathrm{~min}$ before the scopolamine injection. Although this regimen did not conform to the postscopolamine injection procedure

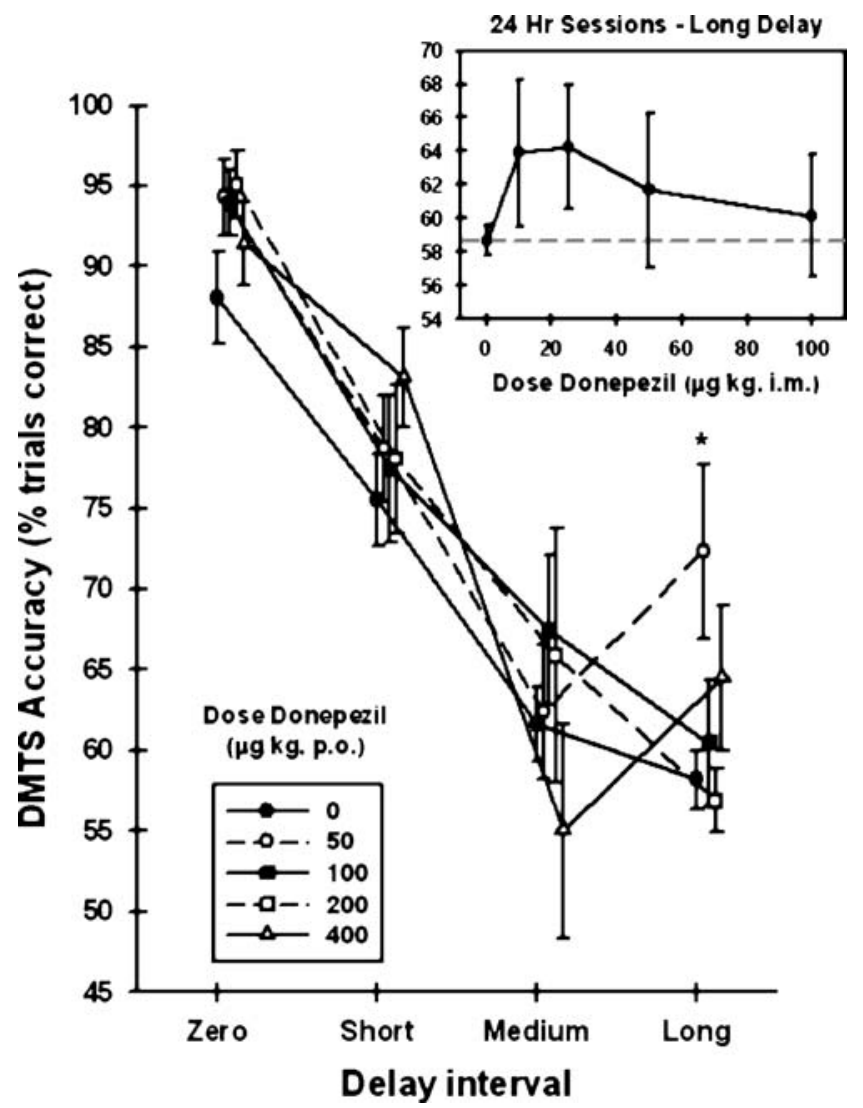

Fig. 5 The effect of oral administration of four doses donepezil on the performance accuracy by Rhesus monkeys well trained in the DMTS task. Asterisk, significantly different from respective mean values in the vehicle $(0 \mu \mathrm{g} / \mathrm{kg})$ group, $P<0.05$. Inset: The effect of donepezil on long-delay trial accuracy during sessions run $24 \mathrm{~h}$ after drug administration plotted as a function of donepezil dose 

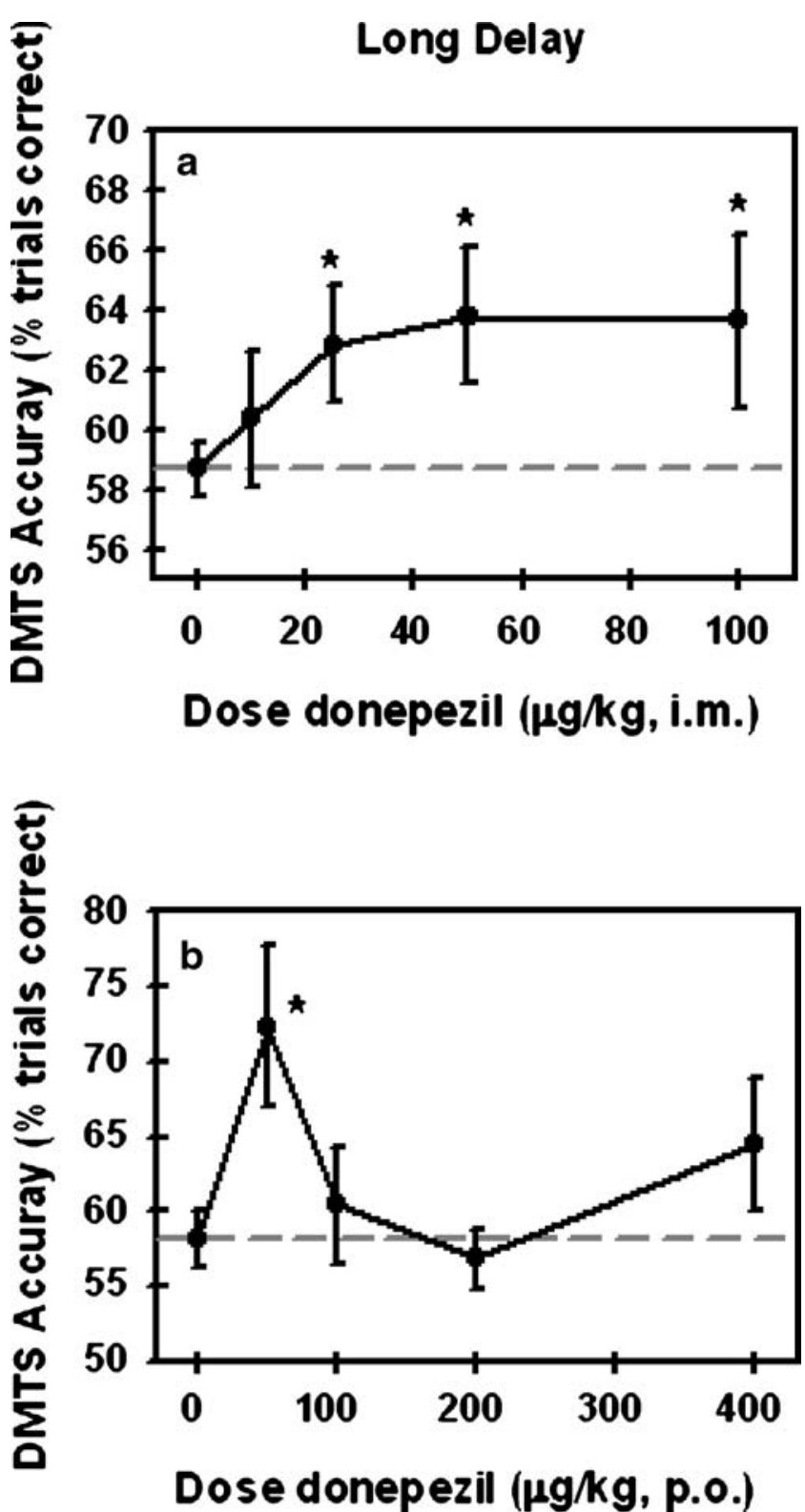

Fig. 6 Comparison of the effects of four doses of donepezil administered by the $\mathbf{a}$ i.m. or $\mathbf{b}$ oral route of administration in Rhesus monkeys on DMTS task accuracies associated with long-delay trials. Asterisk, significantly different from respective mean value in the vehicle $(0 \mu \mathrm{g} / \mathrm{kg})$ group, $P<0.05$

used in the rat studies, donepezil has a sufficiently long duration of action so as not to confound any comparisons between the two species. The dose-response data shown in Fig. 8 are separated into three graphs to simplify visual comparison of the drug effects. In each graph, the scopolamine data are represented by the open circles. Differences between mean scopolamine and the DMTS accuracies were addressed in the preceding section. Overall, there was a dose-dependent $\times$ delay-dependent effect of drug treatment $\left(F_{21,719}=3.05, P<0.0001\right)$. The ability of donepezil to partly reverse the decrements in task accuracy produced by scopolamine was relegated to short-delay trials. The effect was statistically significant for the $10-(t=2.4, P=0.019)$ and the $50-\mu \mathrm{g} / \mathrm{kg}(t=2.5, P=0.013)$ doses of donepezil (Fig. $8 \mathrm{~b}$ and $\mathrm{c}$ ). The biphasic nature of the response is more easily visualized in Fig. 8c.

Because of the complexity of the dose-response relationship, an individual best dose (most effective in reversing the scopolamine decrement in average task accuracy) was selected for each subject. The distribution of best doses of donepezil was as follows: $5 \mu \mathrm{g} / \mathrm{kg}$ —one subject, $10 \mu \mathrm{g} / \mathrm{kg}$ two subjects, $25 \mu \mathrm{g} / \mathrm{kg}$ - three subjects, $50 \mu \mathrm{g} / \mathrm{kg}$ - three subjects, providing an average best dose of $27.8 \mu \mathrm{g} / \mathrm{kg}$. The accuracy data are presented in Fig. 9. There was a statistically significant effect of drug treatment $\left(F_{2,88}=25.4, P<0.0001\right.$; independent factor). The decreases in task accuracy produced by scopolamine $(t=3.4, P=0.001)$ were significantly reversed by the best dose of donepezil during short- $(t=3.2$, $P=0.0019)$ and medium-delay $(t=2.3, P=0.024)$ trials. The effect at zero-delay trials was nearly significant $(t=1.7, P=$ 0.095). Even considering the best dose of donepezil, the drug did not completely reverse the accuracy decrements produced by scopolamine, as there was still a significant difference

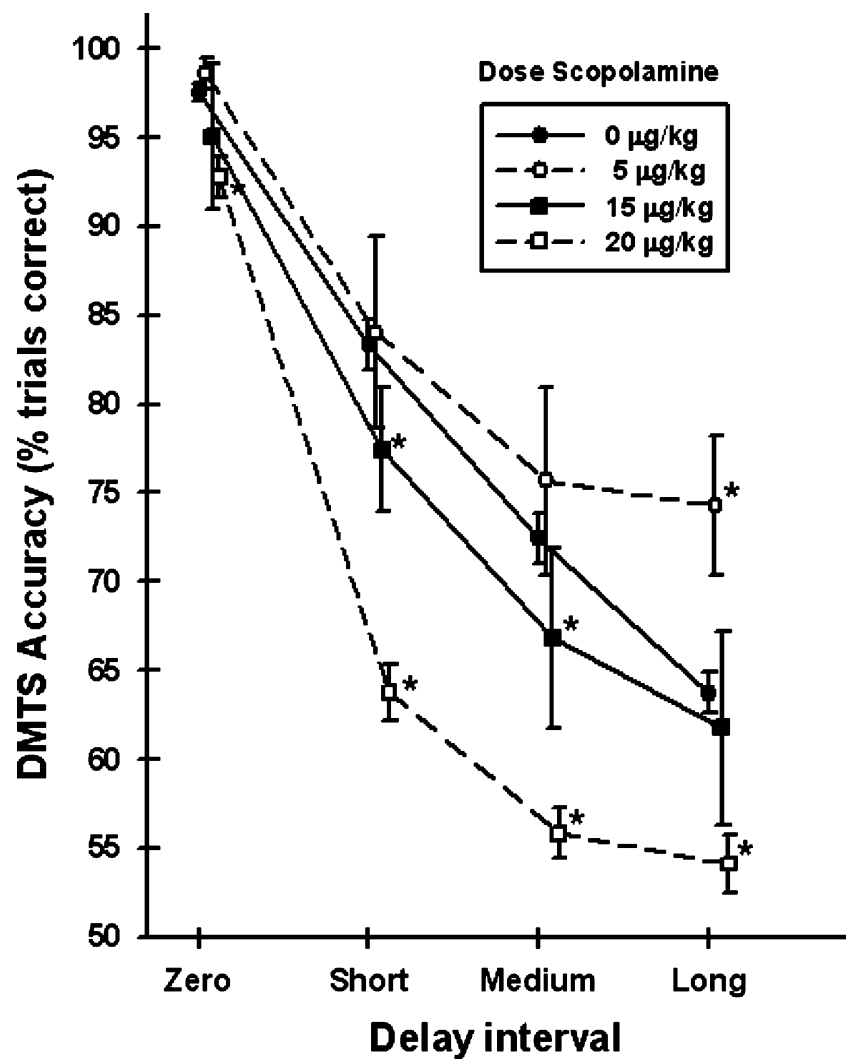

Fig. 7 The effect of i.m. administration of three doses of scopolamine on the performance accuracy by Rhesus monkeys well trained in the DMTS task. Asterisk, significantly different from respective mean values in the vehicle $(0 \mu \mathrm{g} / \mathrm{kg})$ group, $P<0.05$ 
Fig. 8 The ability of donepezil to reverse the decrements in DMTS task accuracy by scopolamine in Rhesus monkeys. Donepezil treatment preceded scopolamine by $10 \mathrm{~min}$, and testing was initiated $30 \mathrm{~min}$ after scopolamine treatment. In each graph, the open circles refer to the group that received the saline (vehicle)-scopolamine $(20 \mu \mathrm{g} / \mathrm{kg})$ regimen. a Comparison of the DTMS task accuracies achieved during standard DMTS sessions (Std DMTS), with accuracies achieved after $20 \mu \mathrm{g} / \mathrm{kg}$ scopolamine (Scop), and with accuracies achieved after $5 \mu \mathrm{g} / \mathrm{kg}$ donepezil followed by scopolamine. b Comparison of the DTMS task accuracies achieved after $20 \mu \mathrm{g} / \mathrm{kg}$ scopolamine (Scop), with accuracies obtained after $10 \mu \mathrm{g} / \mathrm{kg}$ donepezil followed by scopolamine and with accuracies obtained after $25 \mu \mathrm{g} / \mathrm{kg}$ donepezil followed by scopolamine. c Comparison of the DTMS task accuracies achieved after $20 \mu \mathrm{g} / \mathrm{kg}$ scopolamine (Scop), with accuracies obtained after $50 \mu \mathrm{g} / \mathrm{kg}$ donepezil followed by scopolamine and with accuracies obtained after $100 \mu \mathrm{g} / \mathrm{kg}$ donepezil followed by scopolamine. Asterisk, significantly different from respective mean values in the vehicle $(0 \mu \mathrm{g} / \mathrm{kg}$ ) group, $P<0.05$. d The effect of donepezil in scopolamine-treated monkeys on shortdelay trial accuracies plotted as a function of donepezil dose
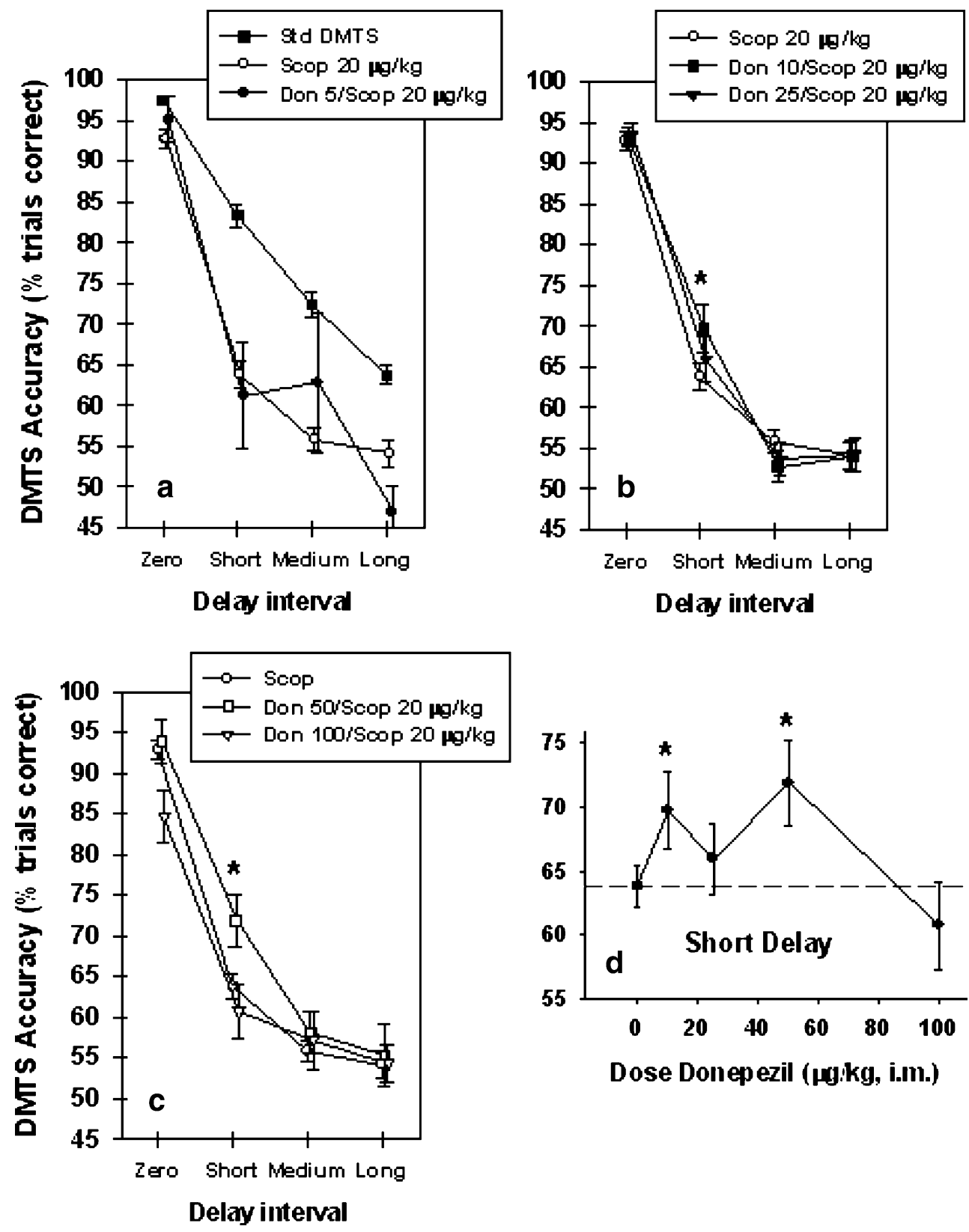

between the standard DMTS response and the donepezil best dose + scopolamine response $(t=3.7, P=0.0004)$. The 10 - and $25-\mu \mathrm{g} / \mathrm{kg}$ doses of donepezil did completely reverse the increase in choice latency produced by scopolamine $\left(F_{6,174}=\right.$ 5.1, $P<0.0001$ ), but higher doses did not (data not shown). In fact, the $125-\mu \mathrm{g} / \mathrm{kg}$ dose was actually associated with greater mean choice latencies than the vehicle $(t=3.7, P=$ 0.0004).

\section{Discussion}

Donepezil is the most widely prescribed drug for the treatment of AD-related cognitive symptoms. The compound is likely to serve as standard by which all new treatments are compared for the foreseeable future. As indicated in "Introduction," there appears to be a renewed interest in reversible models for $\mathrm{AD}$ that can easily be applied in clinical studies. In this study, we confirm the ability of scopolamine to impair the performance of memory-related tasks by rats and monkeys. In the water maze task, the antagonist clearly prevented task acquisition and impaired probe trial accuracy relative to the vehicle. In the rat DSDT task, scopolamine produced a profound impairment of task accuracies, particularly during short-delay trials. The doses used to produce these effects were somewhat higher (100 and $50 \mu \mathrm{g} / \mathrm{kg}$, respectively), than the test dose of scopolamine used in the monkeys $(20 \mu \mathrm{g} / \mathrm{kg})$. The latter dose was more in keeping with the $2-$ 


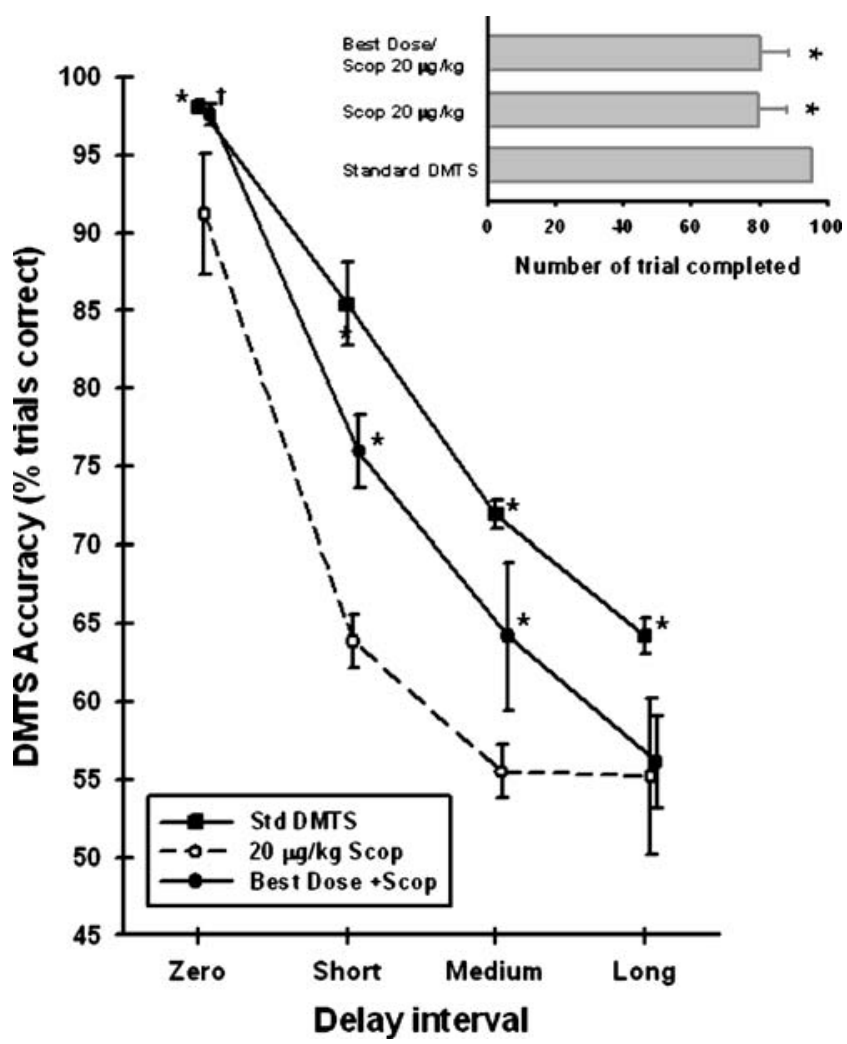

Fig. 9 The ability of the individual best dose (most effective in reversing the scopolamine-induced decrement in average task accuracy) of donepezil to reverse the decrements in DMTS task accuracy by scopolamine in Rhesus monkeys. Donepezil treatment preceded scopolamine by $10 \mathrm{~min}$, and testing was initiated $30 \mathrm{~min}$ after scopolamine treatment. Standard DMTS Standard DMTS accuracy (no drug treatment), Scop $20 \mu \mathrm{g} / \mathrm{kg}$ control scopolamine treatment group with saline pretreatment, Best Dose $/$ Scop $20 \mu \mathrm{g} / \mathrm{kg}$ the best dose of donepezil $+20 \mu \mathrm{g} / \mathrm{kg}$ scopolamine. Asterisk, Significantly different from respective mean values in the $20 \mu \mathrm{g} / \mathrm{kg}$ Scop group, $P<0.05$. Inset: The effect of the three treatment regimens on the number of trials completed per session

$10 \mu \mathrm{g} / \mathrm{kg}$ dose range used in healthy human volunteers (Preston et al. 1988; Molchan et al. 1990; Ray et al. 1992; Lines et al. 1993; Snyder et al. 2005). Scopolamine-induced impairment in task acquisition in the spatial memory task and in the proximate stages of memory formation, i.e., attention and vigilance, in the operant-conditioning tasks is also in keeping with similar effects reported in human subjects (Wesnes and Warburton 1984; Dunne and Hartley 1985; Preston et al. 1989; Sunderland et al. 1989; Duka et al. 1996). In monkeys (and possibly in the rats performing the DSDT task), the memory retention curve (Fig. 9) was shifted to the left suggesting impaired attention, information processing, and recall (Paule et al. 1998), where all three memory impairments have been characterized in $\mathrm{AD}$ (see Jones et al. 1991; Ebert and Kirch 1998; Berardi et al. 2005; Hao et al. 2005).

Indeed, there has been some controversy as to the relevance of the amnestic actions of scopolamine to the memory impairments associated with AD. Some of the controversy clearly has been related to the types of tests administered, the age or disease status of the subjects, and the dose of scopolamine. Our results in monkeys differ to a small degree from those reported by Taffe et al. 1999 who studied the effects of scopolamine in a computer-presented delayed non-matching-to-sample task. In that study, the scopolamine-induced impairment of task accuracy was reported to be delay independent. This clearly was not the case in the present study wherein scopolamine was more effective in decreasing accuracies associated with short- and mediumdelay trials than with zero-delay trials. In fact, in a study with human subjects who performed a DMTS, scopolamine more effectively impaired delayed matching, as compared with simultaneous matching (Koller et al. 2003). The authors concluded that scopolamine has significant impairing effects on memory in addition to its ability to impair attention and that the scopolamine model closely resembled the cognitive impairment associated with AD.

One surprising finding in the scopolamine dose-response series in monkeys was the significant improvement in task accuracy measured after the lowest $(5 \mu \mathrm{g} / \mathrm{kg})$ dose (Fig. 7). The effect was selective for long-delay trials, but the trend also was evident during medium-delay trials. The improvement in mean long-delay accuracy increased from 63.8 to $74.3 \%$ trials correct (16\% increase from the vehicle). This level of task improvement is in the range of several established cognition-enhancing agents (Buccafusco and Terry 2000). We had noted a similar dose-response profile for the nicotinic antagonist mecamylamine, with high doses producing the expected amnestic response and the lowest dose producing improvement in task accuracy (Terry et al. $1999 \mathrm{a}, \mathrm{b})$. It is not clear whether this phenomenon is relegated to cholinergic antagonists, but for scopolamine, the apparent procognitive response subsequent to low-dose administration is most likely related to the ability of the drug to preferentially block presynaptic inhibitory muscarinic receptors (likely the M2 or M4 subtypes) leading to an increase in the release of synaptic acetylcholine. The expected amnestic response occurs when the dose is increased sufficiently to inhibit postsynaptic muscarinic receptors (likely the M1 or M3 subtypes). Drugs like scopolamine and atropine have been demonstrated to produce paradoxical parasympathomimetic actions based on a similar mechanism of action (Wellstein and Pitschner 1988). Another paradoxical response was noted after scopolamine treatment in the rat DSDT task. As indicated in Fig. 3, scopolamine produced a significant dose-dependent decrease in choice latencies. This result was surprising in view of the known ability of scopolamine to slow psychomotor speed in monkeys (Taffe et al. 1999) and in humans (Duka et al. 1996). One explanation pertains to our unpublished observation that oftentimes, choice latencies 
decrease on incorrect trials and the number of incorrect trials increases with the dose of scopolamine. In support of this possibility was the ability of the donepezil treatment to fully reverse scopolamine's effects on choice latencies - as the cholinesterase inhibitor also increased task accuracy. We also noted that scopolamine slightly but significantly increased swim speed in the water maze task, although it is not clear whether this effect of scopolamine is mechanistically related to the shortened latencies produced in the DSDT. The increase in motor speed noted in rats after scopolamine treatment might be species specific because in the monkeys, scopolamine tended to increase median choice latencies, a response more in keeping with that reported for human studies with the drug (Duka et al. 1996).

Donepezil, as we have demonstrated here and published previously (Buccafusco et al. 2003; Buccafusco and Terry 2004), can improve DMTS task accuracy in both young and aged monkeys. In this study, however, there was a difference noted between the dose-response profiles for i.m. vs oral administration. Although both routes of administration produced similar maximal levels of task improvement, after oral dosing, significant task improvement was noted only after one $(50 \mu \mathrm{g} / \mathrm{kg})$ of the four doses (Fig. 6). A narrow dose window is characteristic of the response profile to donepezil as it is used clinically. One possibility is that the oral route is associated with increased potential for side effects, possibly gastrointestinal in nature. Parasympathomimetic side effects could play a role in limiting the effective dose range for orally administered cholinesterase inhibitors in general (Roman and Rogers 2004; Thompson et al. 2004). Another unexpected result was the apparent carryover action of donepezil $24 \mathrm{~h}$ after drug administration. Although the effect did not reach statistical significance, the mean longdelay accuracy after every dose exceeded that for vehicle treatment (Fig. 4, inset). The carryover of donepezil's actions to the following day after administration could reflect the drug's long $(70 \mathrm{~h})$ elimination half-life (Roman and Rogers 2004). This protracted improvement in task accuracy also was evident after orally administered donepezil (Fig. 5, inset). Again, the effect was not statistically significant, but unlike the response measured during the earlier session, the response measured $24 \mathrm{~h}$ later appeared to occur over more than the single dose (compare Fig. 5, inset with Fig. 6b). One possibility is that side effects resolved overnight allowing the beneficial mnemonic effects of the higher doses to partly manifest.

Donepezil treatment was effective in significantly but partially reversing the scopolamine-induced impairment in all three tasks. The effective dose of donepezil in rats in the water maze task was $2 \mathrm{mg} / \mathrm{kg}$, whereas the maximally effective dose in the DSDT task was $1 \mathrm{mg} / \mathrm{kg}$. The most effective dose of donepezil in the DMTS task in monkeys was only $50 \mu \mathrm{g} / \mathrm{kg}$. Thus, the dose of donepezil we used in monkeys to reverse the effects of scopolamine was quite similar (about $70 \mu \mathrm{g} / \mathrm{kg}$ ) to that used in an acute dose scopolamine-reversal study in humans (Snyder et al. 2005). The progression of increasing effective doses of donepezil in the three tasks could reflect the progressively higher doses of scopolamine required to induce the memory impairment in each model. It is quite clear, however, that the doses of cholinergic antagonist and agonist used in monkeys were more similar to those used clinically than those used in rats. As mentioned above, the failure of donepezil to completely reverse scopolamine deficits could be related to the potential for the cholinesterase inhibitor to induce rather severe side effects at doses that might be sufficient to fully reverse the effects of the antagonist.

We have used a computer-assisted version of the DMTS task for more than 15 years to study the cognition-enhancing effects of drugs from several pharmacological classes in young and aged animals. The paradigm has proven successful in predicting the utility of novel compounds in terms of clinical applications (see Buccafusco and Terry 2000; Youdim and Buccafusco 2005). The inclusion of scopolamine in the model provides an added degree of clinical relevance, and as indicated in "Introduction," the ability to reverse the effects of the muscarinic receptor antagonist is not limited to cholinergic agonists. The profiles of the responses in terms of the memory retention curves established when donepezil is used alone or in conjunction with scopolamine are not identical. Alone, donepezil improves task performance associated mainly with long-delay trials. This was true after both i.m. and oral administration. Little potential was demonstrated for the more proximate components of memory consolidation. In contrast, in the scopolamine model (in the DSDT and DMTS tasks), donepezil appeared to exert more selective improvement on short-delay trials, with little or no effect on long-delay trials. The short-delay profile suggests an ability of the drug to affect the more proximate components of memory. These results suggest that drugs like donepezil might have different mnemonic actions in normal subjects or age-impaired subjects as opposed to the drug's actions in demented subjects.

From the data derived from these experiments, it seems reasonable to conclude that scopolamine reversal has a value as a relevant preclinical model for estimating the therapeutic potential of novel cognition-enhancing drugs. For translational effectiveness, the monkey DMTS task could provide a valuable step in determining lead compound status before engaging in clinical evaluations, which incur the most risk from both human safety and financial standpoints. If primate resources are not available, operant-conditioning tasks in rats such as the DSDT constitute perhaps the most desirable rodent models. Useful features of the DSDT task include the ability to induce a mnemonic demand (increasing delay 
intervals) and the ability to use the subjects repeatedly (after washout) and as their own controls. Application of the scopolamine reversal to both monkey and rodent tasks adds a relevant dimension to already very useful models.

Acknowledgments The authors would like thank Nancy Kille for her excellent assistance with the primate studies. This work was supported in part by the Medical College of Georgia Alzheimer's Research Center, the Veterans Administration Medical Center, and Abbott Laboratories.

\section{References}

Aubert I, Araujo DM, Cecyre D, Robitaille Y, Gauthier S, Quirion R (1992) Comparative alterations of nicotinic and muscarinic binding sites in Alzheimer's and Parkinson's diseases. J Neurochem 58:529-541

Bain JN, Prendergast MA, Terry AV Jr, Arneric SP, Smith MA, Buccafusco JJ (2003) Enhanced attention in Rhesus monkeys as a common factor for the cognitive effects of drugs with abuse potential. Psychopharmacology 169:150-160

Bartus RT (1978) Evidence for direct cholinergic involvement in the scopolamine-induced amnesia in monkeys: effects of concurrent administration of physostigmine and methylphenidate with scopolamine. Pharmacol Biochem Behav 9:833-836

Bartus RT, Dean RL, Flicker C (1987) Cholinergic pharmacology: an integration of human and animal research on memory. In: Meltzer HY (ed) Psychopharmacology: the third generation of progress. Raven, New York, pp 219-232

Beglinger LJ, Tangphao-Daniels O, Karaken D, Zhang L, Mohs R, Siemers ER (2005) Neuropsychological test performance in healthy elderly volunteers before and after donepezil administration: a randomized controlled study. J Clin Psychopharmacol 25: $159-165$

Bejar C, Wang RH, Weinstock M (1999) Effect of rivastigmine on scopolamine-induced memory impairment in rats. Eur J Pharmacol 383:231-240

Berardi AM, Parasuraman R, Haxby JV (2005) Sustained attention in mild Alzheimer's disease. Dev Neuropsychol 28:507-537

Blackwell AD, Sahakian BJ, Vesey R, Semple J, Robbins TW, Hodges JR (2004) Detecting dementia: novel neuropsychological markers of preclinical AD. Dement Geriatr Cogn Disord 17:42-48

Buccafusco JJ, Terry AV Jr (2000) Multiple CNS targets for eliciting beneficial effects on memory and cognition. J Pharmacol Exp Ther 295:438-446

Buccafusco JJ, Terry AV Jr (2004) Donepezil-induced improvement in delayed matching accuracy by young and old rhesus monkeys. J Molec Neurosci 24:85-91

Buccafusco JJ, Terry AV Jr, Murdoch PB (2002) A computer assisted cognitive test battery for aged monkeys. J Molec Neurosci 19: $179-185$

Buccafusco JJ, Jackson WJ, Stone JD, Terry AV Jr (2003) Sex dimorphisms in the cognitive-enhancing action of the Alzheimer's drug donepezil in aged rhesus monkeys. Neuropharmacology 44:381-389

Collie A, Maruff P (2000) The neuropsychology of preclinical AD and mild cognitive impairment. Neurosci Biobehav Rev 24:365374

Collie A, Maruff P, Currie J (2002) Behavioral characterization of mild cognitive impairment. J Clin Exp Neuropsychol 24:720-733

de Bruin N, Pouzet B (2006) Beneficial effects of galantamine on performance in the object recognition task in Swiss mice: deficits induced by scopolamine and by prolonging the retention interval. Pharmacol Biochem Behav 85:253-260
Drachman DA, Leavitt J (1974) Human memory and the cholinergic system. Arch Neurol 30:113-121

Duka T, Ott H, Rohloff A, Voet B (1996) The effects of a benzodiazepine receptor antagonist beta-carboline ZK-93426 on scopolamine-induced impairment on attention, memory and psychomotor skills. Psychopharmacology 123:361-373

Dunne MP, Hartley LR (1985) The effects of scopolamine upon verbal memory: evidence for an attentional hypothesis. Acta Psychol 58:205-217

Ebert U, Kirch W (1998) Scopolamine models of dementia: electroencephalogram findings and cognitive performance. Eur J Clin Invest 28:944-949

Evans-Martin F, Terry Jr AV, Jackson WJ, Buccafusco JJ (2000) Evaluation of two rodent tasks: a method with retracting levers versus a method with closing doors. Physiol Behav 70:233-241

Hao J, Li K, Li K, Zhang D, Wang W, Yang Y, Yan B, Shan B, Zhou $\mathrm{X}$ (2005) Visual attention deficits in Alzheimer's disease: an fMRI study. Neurosci Lett 385:18-23

Heise GA (1984) Behavioral methods for measuring effects of drugs on learning and memory in animals. Med Res Rev 4:535-538

Jones RW, Wesnes KA, Kirby J (1991) Effects of NMDA modulation in scopolamine dementia. Ann NY Acad Sci 640:241-244

Koller G, Satzger W, Adam M, Wagner M, Kathmann N, Soyka M (2003) Effects of scopolamine on matching-to-sample paradigm and related testes in human subjects. Neuropsychobiology 48: $87-94$

Lieben CK, Blokland A, Sik A, Sung E, van Nieuwenhuizen P, Schreiber R (2005) The selective 5-HT6 receptor antagonist Ro4368554 restores memory performance in cholinergic and serotonergic models of memory deficiency in the rat. Neuropsychopharmacology 30:2169-2179

Lindner MD, Hogan JB, Hodgers DB Jr, Orie AF, Chen P, Corsa JA, Leet JE, Gillman KW, Rose GM, Jones KM, Gribkoff VK (2006) Donepezil primarily attenuates scopolamine-induced deficits in psychomotor function, with moderate effects on simple conditioning and attention, and small effects on working memory and spatial mapping. Psycopharmacology 188:629-640

Lines CR, Ambrose JH, Heald A, Traub M (1993) A double-blind, placebo-controlled study of the effects of eptastigmine on scopolamine-induced cognitive deficits in healthy male subjects. Hum Psychopharmacol 8:271-278

Mewaldt SP, Ghoneim MW (1978) The effects and interactions of scopolamine, physostigmine and methamphetamine on human memory. Pharmacol Biochem Behav 10:205-210

Misane I, Ogren SO (2003) Selective 5-HT1A antagonists WAY 100635 and NAD-299 attenuate the impairment of passive avoidance caused by scopolamine in the rat. Neuropsychopharmacology 28:253-264

Molchan SE, Mellow AM, Lawlor BA, Weingartner HJ, Cohen RM, Cohen MR, Sunderland T (1990) TRH attenuates scopolamineinduced memory impairment in humans. Psychopharmacology 100:84-89

Paule MG, Bushnell PJ, Maurissen JPJ, Wenger GR, Buccafusco JJ, Chelonis JJ, Elliott R (1998) Symposium overview: the use of delayed matching-to-sample procedures in studies of short-term memory in animals and humans. Neurotoxicol Teratol 20:493502

Prendergast MA, Jackson WJ, Terry AV Jr, Kille NJ, Arneric SP, Buccafusco JJ (1998) Age-related differences in distractibility and response to methylphenidate in monkeys. Cereb Cortex 8:164-172

Preston GC, Brazell C, Ward C, Broks P, Traub M, Stahl SM (1988) The scopolamine model of dementia: determination of central cholinomimetic effects of physostigmine on cognition and biochemical markers in man. J Psychopharmacol 2:67-79

Preston GC, Ward C, Lines CR, Poppleton P, Haigh JR, Traub M (1989) Scopolamine and benzodiazepine models of dementia: 
cross-reversals by Ro 15-1788 and physostigmine. Psychopharmacology 98:487-494

Ray PG, Meador KJ, Loring DW, Zamrini EW, Yang X-H, Buccafusco JJ (1992) Central anticholinergic hypersensitivity in aging. J Geriatr Psychiatry Neurol 5:72-77

Reidel W, Hogervorst E, Leboux R, Verhey F, van Praag H, Jolles J (1995) Caffeine attenuates scopolamine-induced memory impairment in humans. Psychopharmacology 122:158-168

Roman GC, Rogers SJ (2004) Donepezil: a clinical review of current and emerging indications. Expert Opin Pharmacother 5: 161180

Rossor M, Iversen LL (1986) Non-cholinergic neurotransmitter abnormalities in AD. Br Med Bull 42:70-74

Smith CM, Swash M (1978) Possible biochemical basis of memory disorder in AD. Ann Neurol 3:471-473

Snyder PJ, Bednar MM, Cromer JR, Maruff P (2005) Reversal of scopolamine-induced deficits with a single dose of donepezil, an acetylcholinesterase inhibitor. J Alzheimer's Dis Dement 1: $126-135$

Sunderland T, Weingartner H, Cohen RM, Tariot PN, Newhouse PA, Thompson KE, Lawlor BA, Mueller EA (1989) Low-dose oral lorazepam administration in Alzheimer subjects and agematched controls. Psychopharmacology 99:129-133

Taffe MA, Weed MR, Gold LH (1999) Scopolamine alters rhesus monkey performance on a novel neuropsychological test battery. Cogn Brain Res 8:203-212

Takahata K, Minami A, Kusumoto H, Shimazu S, Yoneda F (2005) Effects of selegiline alone or with donepezil on memory impairment in rats. Eur J Pharmacol 518:140-144

Terry AV Jr, Buccafusco JJ, Jackson WJ, Zagrodnik S, Evans-Martin FF, Decker MW (1996) Effects of stimulation or blockade of central nicotinic-cholinergic receptors on performance of a novel version of the rat stimulus discrimination task. Psychopharmacology 123:172-181
Terry AV Jr, Buccafusco JJ, Decker MW (1997) Cholinergic channel activator, ABT-418, enhances delayed-response accuracy in rats. Drug Dev Res 40:304-312

Terry AV Jr, Gattu M, Buccafusco JJ, Sowell JW, Kosh JW (1999a) Ranitidine analog, JWS-USC-75IX, enhances memory-related task performance in rats. Drug Dev Res 47:97-106

Terry AV Jr, Buccafusco JJ, Prendergast MA (1999b) Dose-specific improvements in memory-related task performance by rats and aged monkeys administered the nicotinic-cholinergic antagonist mecamylamine. Drug Dev Res 47:127-136

Terry AV Jr, Buccafusco JJ, Prendergast MA (2003) The cholinergic hypothesis of $\mathrm{AD}$ : recent challenges and their implications for novel drug development. J Pharmacol Exp Ther 306:821-827

Thompson S, Lanctot KL, Herrmann N (2004) The benefits and risks associated with cholinesterase inhibitor therapy in AD. Expert Opin Drug Saf 3:425-440

van der Staay FJ, Bouger PC (2005) Effects of the cholinesterase inhibitors donepezil and metrifonate on scopolamine-induced impairments in the spatial cone field orientation task in rats. Behav Brain Res 156:1-10

Van Dam D, De Deyn PP (2006) Drug discovery in dementia: the role of rodent models. Nat Rev Drug Discovery 5:956-970

Van Kampen M, Selbach K, Schneider R, Schiegel E, Boess F, Schreiber R (2004) AR-R 17779 improves social recognition in rats by activation of nicotinic alpha7 receptors. Psychopharmacology 172:375-383

Wellstein A, Pitschner HF (1988) Complex dose-response curves of atropine in man explained by different functions of M1- and M2cholinoceptors. Naunyn-Schmiedebergs Arch Pharmakol 338:19-27

Wesnes K, Warburton DM (1984) Effects of scopolamine and nicotine on human rapid information processing performance. Psychopharmacology 82:147-150

Youdim MBH, Buccafusco JJ (2005) CNS targets for multi-functional drugs in the treatment of neurodegenerative diseases. J Neural Transm 112:519-537 